\title{
The Role of Loose Spaces In absorbing and regulating the act of appropriation in urban environment AL- Tahrir SQ.and AL-Ummah Garden as a case study
}

\author{
Nada Azzam Mahmood ${ }^{1}$, Asmaa Mohammed Hussain Al-Muqaram² \\ \{ arch.nada1984@gmail.com $^{1}, \underline{90044 @ \text { uotechnology.edu.iq }}{ }^{2}$ \} \\ Al-Nahrain University- Department of Architectural Engineering ${ }^{1}$, University of Technology- Department of \\ Architectural Engineerig ${ }^{2}$
}

\begin{abstract}
Public space colonization and privatization in the world generally and in Baghdad particularly lead to modeled environments, put individuals in passive consumer role and determines its path. Reflexive behaviors appear to resist theses rigid circumstances represented in appropriating public space according to their needs. Accordingly, research problem addressed as "absence of clear knowledge about the role of loose spaces in realizing and organizing appropriation act in urban environment". The study seeks to discover type of appropriation and how they can be organized with other interactions in urban space". The research was based on the basic hypothesis that "loose spaces have spatial characteristics adapted and varied according to the type of appropriation". The research adopted a qualitative approach based on determining the nature of loose spaces and applying their indicators to elected samples in Baghdad that accommodate temporary appropriations. (AL- Tahrir SQ.and AL-Ummah Garden). The study found that loose spaces attract temporary and informal appropriation which could be intentional, organized or spontaneous and innate, these appropriations could be either positive represented in rights and selfexpression or negative represented in behaviors incompatible with laws customs and social traditions.
\end{abstract}

Key words: loose spaces, appropriation, resistance, self-expression.

\section{Introduction}

Looseness can be referred to as being free, released from tightness and restraint. It is something soft, relaxed, and free from order and regulations. Looseness attached to daily life in different ways, some related to soft physical state of the body, the other related to unrestricted human behaviors. [14] loose spaces as result constructed and formulated according to these activities, and the users will in appropriating that space, the research spot the light on the importance of these appropriation and loose space emerged from them and its reflections on the city .therefore the research divided into 3 main parts : first part spot the light on the importance of looseness in daily life and urban spaces, activities that generate looseness, urban conditions that support its existence, and its potentials and obstructions . Second part spots the light on the appropriation, its relation with time, users and physical characteristics of space and type of appropriation in urban space. Third part analyze and evaluate appropriations in the selected case study of AL- Tahrir SQ.and AL-Ummah Garden in Baghdad.

\section{2-1 Looseness in daily life}

Looseness associated with its contradicting concept "tightness", it puts a little external constraint on individuals, providing wide set of behavioral choices with wide scope of freedom. Looseness refers to cultures with fragile social norms which highly allow abnormal and deviant behaviors.[10]. Looseness is soft lifestyles which avoid rough way of life and call for spontaneous changeable practices, some of them unproductive and non-programmatic, involves discovery, diversity, and risk [4]. Looseness embedded in human nature, force it to resist rigors daily routine, this resistance is evident in institutional spaces characterized by a highly intense environment such as hospitals, jails and schools. These environments create reflexive reactions for the occupants force them to resist tightness and looking for alternative environments, appropriate it to satisfy their needs. [4].

\section{2-2 looseness in urban space}


Looseness can refer to play, the quality of being movable and unattached to physical constraint. [22]. Tight spaces restricts human behaviors and therefore restrict the emergence of looseness, it imposes physical constraint, control human behavior and restrict free choice, it's functional spaces works as what planned for it and the users follow specific rules for that space to achieve what they called "Common Good" . [1]

The concept of loose spaces can be found within designed spaces in urban environment, where the unintended and unplanned go side by side with the intentional and original uses allocated to that space. Loose spaces exist under unofficial conditions, it's one of urban formations depends on urban structure with specific characteristics support their existence [11]. It doesn't have fixed physical entity and it relies on actions and activities of its users. [21]. unlike planned spaces which put rules and restrictions for users to consume it, loose paces depend on productive active users and their ability in finding and exploring its potentials. Its uses stem from complicated set of users need which in turn make full use of it. [17]. These spaces can be found when physical conditions support their existence; such as spaces lost their immediate use and the function for which they were designed are no longer existed. [21]

The procedural definition of loose spaces is a temporal space constructed according to human needs and reaction against strict control on users' desires and choices in public space can be expressed through informal practices sometimes illegal, theses resistance can be seen in finding ways and possibilities to recall their social, political rights in the city.

\section{2-2-1 Activities that generate looseness in public space}

Loose spaces can sustain a wide spectrum of various activities and practices, some of them necessary, positive and movable others are optional, negative and static. Some practices looking for leisure and adventure others just enjoying the city seen and the movement of people passersby. [16]

Loose practices contains various activities such as democratic and expression activities provides opportunities of connections with others, encourage cultural and religious ritual expressions, associated with special events like ceremonies, carnivals and festivals [8].

Frequency and time duration of specific loose activities can determine temporal frequency and time duration of loose spaces and recognize it from tight activities. For example essential activities give less care to the quality of space and carry out in the same frequency whether the space is tight or loose. Its time duration elongate in loose spaces. [9] Whenever the space is loose, the frequency of optional activities increase and the social activities increase subsequently . growing new forms of connections and contacts at which it provide environment for the unexpected, spontaneous and unplanned beside wide range of optional activities. [9].

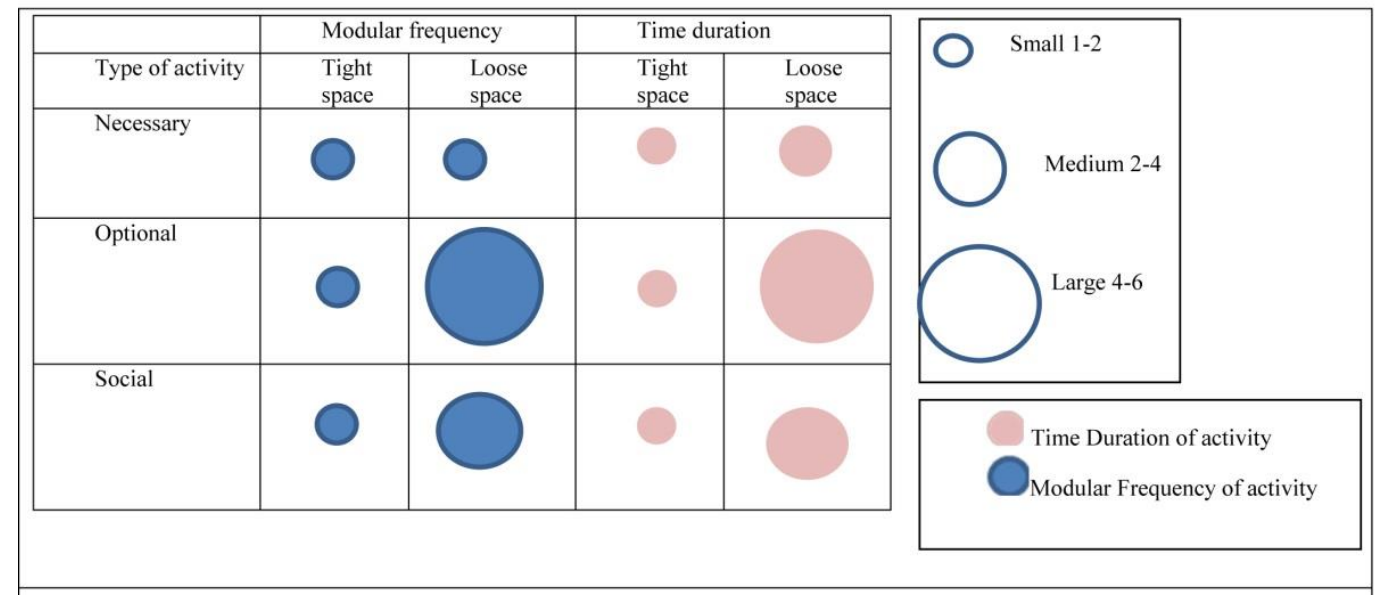

Fig.1. relationship between nature of public space (tight - loose) and the rate of recurrence related to necessary, optional and social activity in the space.

\section{2-3 Urban condition that sustain the existence of loose spaces}

- Regulatory characteristics of buildings such as mixed use neighborhoods consist of buildings with different ages and sizes, weak connection between shape and its function. [12] .

- Multiple separated elevations, multiple entrances attract strangers to interact recurrently, human scale that encourage walking in these streets.

- Movement structure of urban environments which consist of multiple overlapping circulation loops which is dense and intersecting, ringy spaces which is hard to control movement through it, allows personal spaces to connect with occupants movements.

- Neglected and abounded spaces, unspecified for specific function, usually assigned directly near spaces with fixed and specific functions, such as spaces under bridges and near the transport lines, does not have intentional 
use and usually lacks to attractive features. Bridges, for example, carry substrates underneath underworlds that are outside the flow, rush, and continuity of space above them. [3] .

- Neglected buildings, displaced and unclear functions that exist in daily use areas of the city and that are suitable for new and temporary uses. [5] .

- Abandoned functions and spaces that are no longer dedicated to its original function, or had a specific function but were no longer so, which make it open to new uses and meanings.

- Imposed ownership on the place or disputed spaces which lead to complete negligence by its owners.

- Destructive structures that carry clues from previous use, which serve as hints calling for some kind of living and open the imagination of what this space could be.

- Abandoned and neglected spaces that lack official uses and located outside the daily life flow and movement and outside legislation control and supervision. [19].

\section{2-4 Potentials and Obstructions of loose spaces}

Loose spaces have potentials which affect the city positively:

- Adaptability and flexibility :

Material characteristics in loose spaces specialized by ease of change, respond to modification and adjustment, this flexibility stimulate and pave the way towards discovery and creativity. [18] Users adopt and appropriate these possibilities to meet their objective and their special uses. It has overlapping characteristics suits with multiple users' choices, it serves different needs of joy and recreation beside the essential other needs, it encompasses and adapt with various and different activities going side by side in urban environment. It's flexible and adaptable it modifies its physical characteristics regulate it to make the space adaptable to various and multiple uses [18]

\section{- Openness :}

Loose spaces is open -ended, it doesn't have fixed temporal boundary, it encompasses wide spectrum of multiple and various activities in one space, this openness leads to rich sensual experience to produce complex net of multi-sensory and various set of perceptional experience. Overlaps to produce spaces with sensual identity give the space it's cultural and social print, its uniqueness and distinctness.[18]

- identity and self-belonging :

Sustain and reinforce occupants belonging to that space, it achieves societal identity through expressing social and cultural identity freely and engage people in designing spaces of the city.

\section{Obstructions and negative aspects differ according to the location of these spaces and physical characteristics of} it, it can embed:

\section{- Risk and adventures :}

Some loose spaces stimulate suspicious and uncertainty of what might individual's face, beside the chance of being hurts physically according to the neglected buildings and spaces.

- Negative behaviors conflicts with common traditions in society:

Loose spaces may inhabit negative and dangerous behaviors that contradict with social common acceptability, like drinking al-cohol, buying and selling drugs, sexual practices and terrorist behaviors.

- Unorganized and uncivilized appearance :

Some practices may intersect and contradict with daily life practices, attach chaos and unorganized seen to the city. Such as blocking main stream routs or restricting passersby in addition to the chaos organization of goods on the roads. [8]

\section{3- Appropriation:}

Appropriation represents the first act in resisting rigidity and intensity of urban environment. [4] . It's one of people's rights in the city, it represent the right of accessing public space and using it[6]. Appropriation is a socio - spatial need inherent in human innate nature, forces him to use space illegally by informal uses . [13] Appropriation is the first actual practice leads to the existence of loose spaces. [7]. It occurs as a result of prior preference for certain characteristics in that space to suit users desired and loose activities, beginning by identifying different opportunities and possibilities for using space in different way. [8]

\section{3-1 Its relation with time}

Appropriation in loose space is temporary T.A, It is a dynamic phenomenon based on conditional time; it is important factor in loose spaces where people use public spaces for collective or individual activities other than the purpose for which they were designed. [2] Temporal Appropriation is multidimensional associated with cultural scene of the city; 
it's full of meanings and symbols, and constructed socially according to the values, symbols and rituals associated with that space and inherent in it. [2] . Time duration of appropriation differs and varies from place to place and is related to the nature and type of appropriation, some of which may be fleeting others prolonged and may extend over the entire day.

\section{3-2 Its relation to physical characteristics of space}

Appropriation varies in its association with daily and formal practices according to the spaces that embed appropriation. For example dead spaces suspend formal programs replace it with informal activities while edge spaces contain informal activities took place in parallel with formal practices, the third type is when formal and informal activities overlap and intermingle with each other. [8]

\section{3-3 Its relation with users}

Appropriation has an important and active role in urban space, it enables individuals and give them an important role in structuring spaces and give them the right to manage and practice their daily life in an integrated way, transforms users role from being consumer to be active. Purcell 2002 pointed that appropriation don't limited to occupying produced urban area but means the right in producing urban space that satisfies people's needs enables them to participate in creating life of city [17]

\section{3-4 Appropriation and people's right of the city}

The necessity of peoples right in producing the city and being able in controlling the use of the spaces that being constructed in the light of local and global economic transformations [6]. The nature of appropriation existed in urban spaces controlled by capital ideologies; deny the right of others to benefit from public space. Therefore the right of appropriation and occupying public space accompanied with struggle to achieve legal rights fits with users' needs and desires. [6] .

\section{- 3-5 Types of Appropriation}

Nature of appropriation varies, it could be spontaneous and unexpected, or occurs according to a regular schedule and may occur every day, appropriation also varies according to the type of activities (commercial, entertainment, cultural, religion), these activities took place in designed space, compose daily life that connected to the streets and squares, the nature of appropriation differs according to its aims and purposes,

- Commercial appropriation is an activity in which public space is occupied and used by a person or group of persons informally and without obtaining fundamentalist approvals in order to obtain economic benefit directly or indirectly. Although governments and decision-makers do not favor this type of event, it is an activity that individuals around the world use to temporarily occupy space. [2] . See Fig .2.

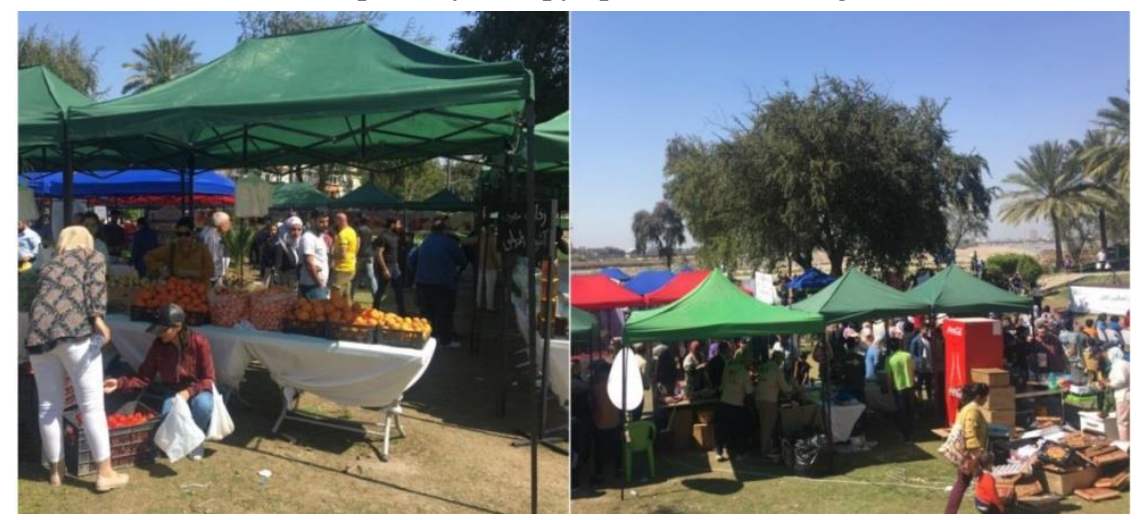

Fig.2. temporal appropriation of space- bazar to support local production support the national product on the occasion of Mother's Day on the gardens of Abu Nawas - date 20/4/2019. Resource ; researcher

- Recreational appropriation is an activity that aims to achieve pleasure and recreation; the residents feel comfortable through emotional participation in the public space and enhance the ownership of the occupant of the place. See Fig .3. 
Fig.3. Spontaneous appropriation of

- Religious

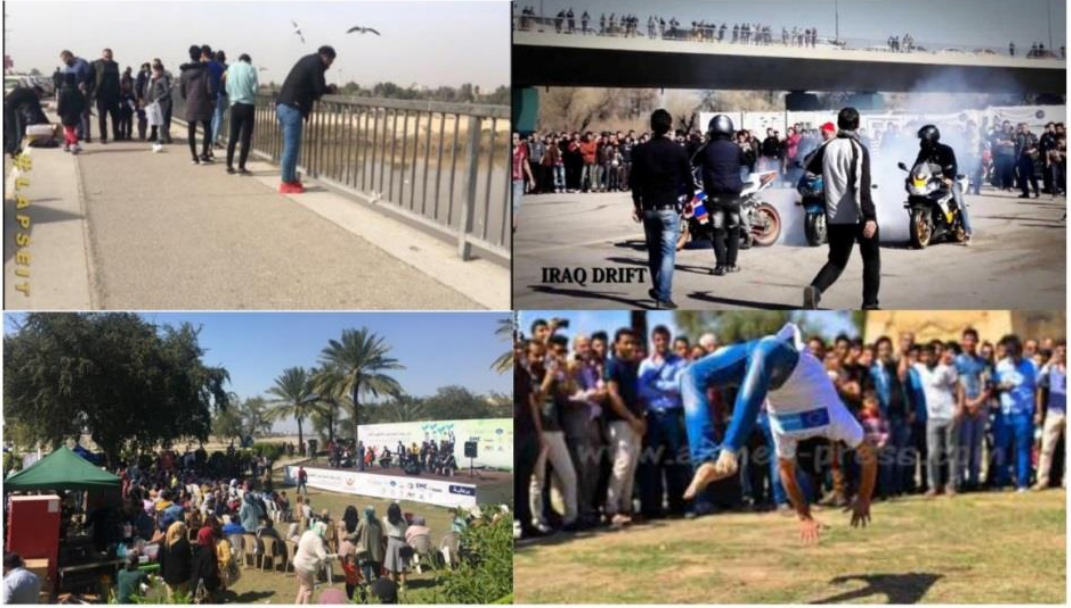

appropriation includes reviving religious and cultural rituals in countries with religious culture and history, where public spaces are temporarily appropriated .see fig.4.

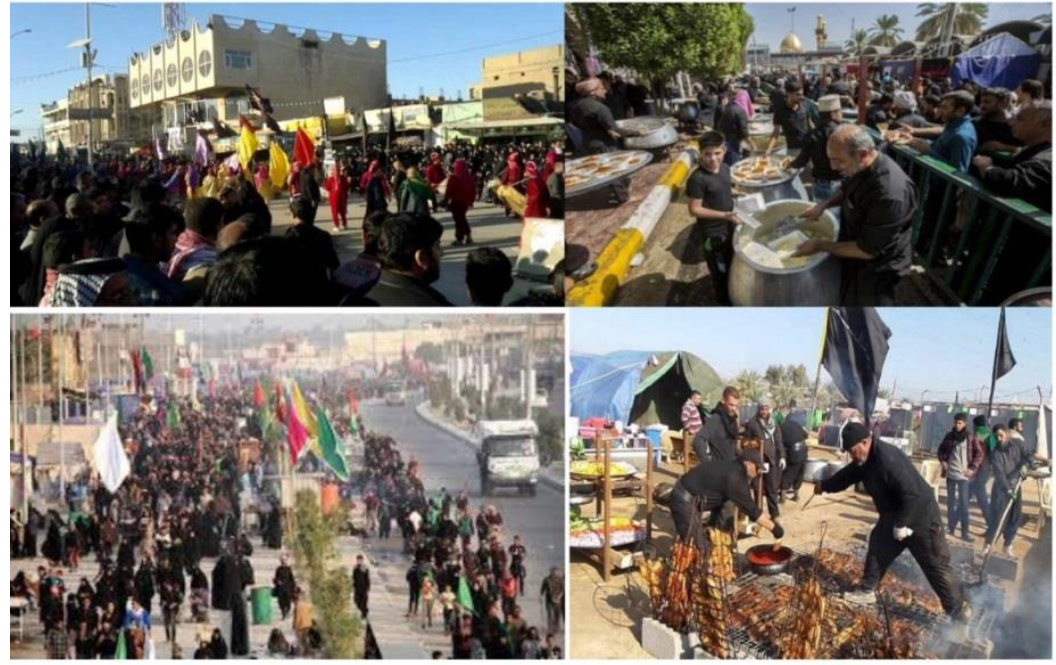

Fig.4. Temporary

religious seizure of space / religious processions in the 40th visit recreational

space

and cultural 
Fig 5. Democratic and political appropriation of space

Whatever the type of appropriation that makes the space loose, it occurs in addition to the intentional functions of it, where the intended and unintended go side by side overlap and interfere to create moments of congestion, possibilities of tension and conflict, these conditions help to generate density, diversity and vitality of life in urban space. [20]

\section{4- Practical - case study}

AL- Tahrir SQ.and AL-Ummah Garden is vital places in Baghdad, dominated by commercial appropriations which last for half a day. At night theses spaces disappears left the area silent like a ghost city. Recently as a result to political events these spaces show different behaviors of appropriation, transforming its permanent daily spaces into temporal spontaneous spaces. These appropriations differs according to the type of activity gender and ages as shown in Table.1 and Fig.6. Shows high percentage of males than women and a low percentage of children.

Table.1 Distribution of users and uses at different times of the day for different groups of users

\begin{tabular}{|l|c|c|c|c|c|}
\hline \multirow{2}{*}{ Type of activity } & \multirow{2}{*}{ children } & \multicolumn{2}{c|}{ teenagers } & \multicolumn{2}{c|}{ infants } \\
\cline { 3 - 6 } & & female & Male & female & Male \\
\hline Commercial & $20 \%$ & $10 \%$ & $80 \%$ & $30 \%$ & $70 \%$ \\
\hline Religion \&cultural & $2 \%$ & $30 \%$ & $70 \%$ & $40 \%$ & $60 \%$ \\
\hline Recreational & $0 \%$ & $5 \%$ & $10 \%$ & $0 \%$ & $0 \%$ \\
\hline Democratic & $0 \%$ & $50 \%$ & $50 \%$ & $30 \%$ & $70 \%$ \\
\hline
\end{tabular}

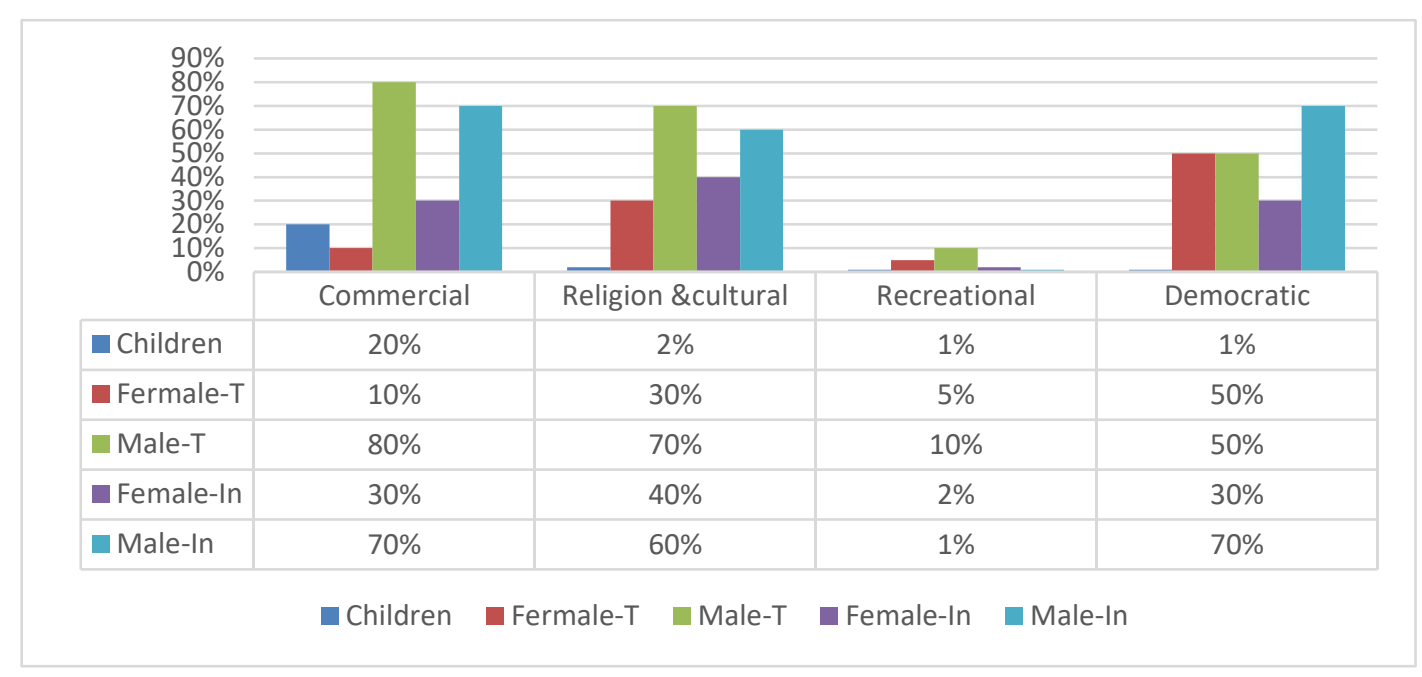

Fig.6 Distribution of Users at Different time

The study shows that appropriation frequencies vary during the day. Also its frequencies and intensity differs in normal days from the days that are characterized by a specific event in the city. Table.2. Table.3. appropriations in protester day shows the ability of appropriations in protester day to transfer rigid daily life into loose spaces . see Fig 8.10.11.12.

Table.2 Measurement of appropriation frequency A during a specific time period during ordinary day.

\begin{tabular}{|c|c|c|c|c|c|c|c|}
\hline \multirow{2}{*}{ Time duration } & \multicolumn{7}{|c|}{ Days of the week } \\
\cline { 2 - 8 } & Sunday & Monday & Tuesday & Wednesday & Thursday & Friday & Saturday \\
\hline 8am-12pm & 10000 & 500 & 450 & 500 & 800 & 20000 & 600 \\
\hline $12 \mathrm{pm}-3 \mathrm{pm}$ & 30000 & 15000 & 1000 & 500 & 900 & 40000 & 500 \\
\hline 3pm-6pm & 20000 & 900 & 95000 & 1000 & 600 & 50000 & 500 \\
\hline 6pm-9pm & 900 & 500 & 500 & 500 & 500 & 30000 & 500 \\
\hline 9pm-12am & 500 & 500 & 500 & 500 & 500 & 1000 & 500 \\
\hline Sum of A & & & & & & & \\
\hline Rate of A & & & & & & & \\
\hline
\end{tabular}


Sum (A): the sum of the total time slots of the appropriation measured during the days of the week,

Rate (A): the average time intervals of the appropriation measured during the days of the week.

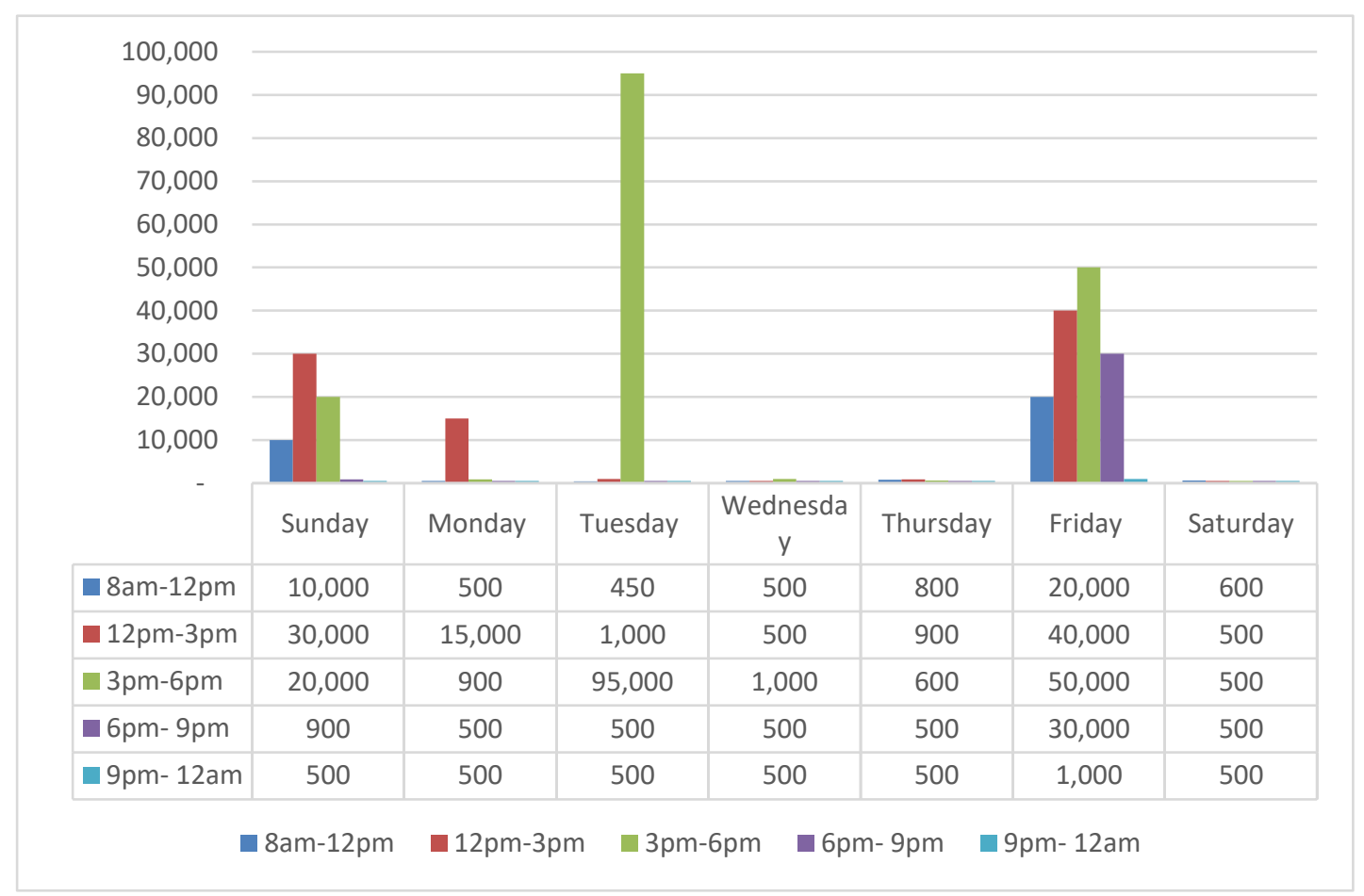

Fig.7 Appropriation Frequencies during ordinary` day

\begin{tabular}{|c|c|}
\hline & $\begin{array}{l}\text { Intense } \\
\text { appropriation } \\
24 \text { hours }\end{array}$ \\
\hline 0 & $\begin{array}{l}\text { Moderate } \\
\text { appropriation } \\
12 \text { hours }\end{array}$ \\
\hline • & $\begin{array}{l}\text { Weak appropriation } \\
2-6 \text { hours }\end{array}$ \\
\hline
\end{tabular}
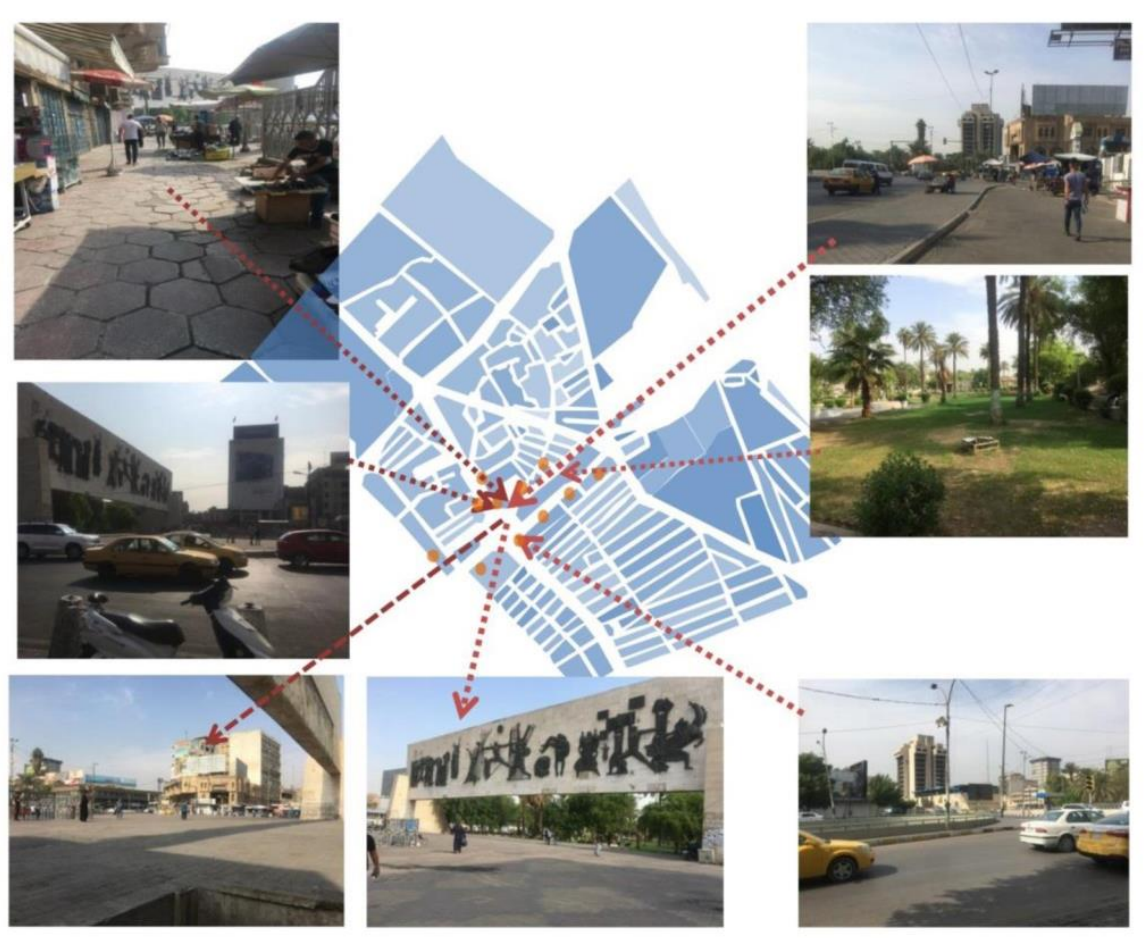

Fig .8. Time duration of appropriation in ordinary day. Researcher 
Table.3 Measurement of appropriation frequency A during a specific time period during protestor day.

\begin{tabular}{|c|c|c|c|c|c|c|c|}
\hline \multirow[t]{2}{*}{ Time duration } & \multicolumn{7}{|c|}{ Days of the week } \\
\hline & Sunday & Monday & Tuesday & Wednesday & Thursday & Friday & Saturday \\
\hline \multicolumn{8}{|l|}{$8 \mathrm{am}-12 \mathrm{pm}$} \\
\hline $12 \mathrm{pm}-3 \mathrm{pm}$ & 2000 & 3000 & 3000 & 3000 & 2000 & 5000 & 5000 \\
\hline $3 \mathrm{pm}-6 \mathrm{pm}$ & 500 & 500 & 500 & 500 & 500 & 700 & 500 \\
\hline $6 \mathrm{pm}-9 \mathrm{pm}$ & 30 & 40 & 30 & 30 & 40 & 150 & 50 \\
\hline 9pm- 12am & 20 & 30 & 10 & 20 & 50 & 60 & 30 \\
\hline \multicolumn{8}{|l|}{ Sum of A } \\
\hline Rate of A & & & & & & & \\
\hline
\end{tabular}

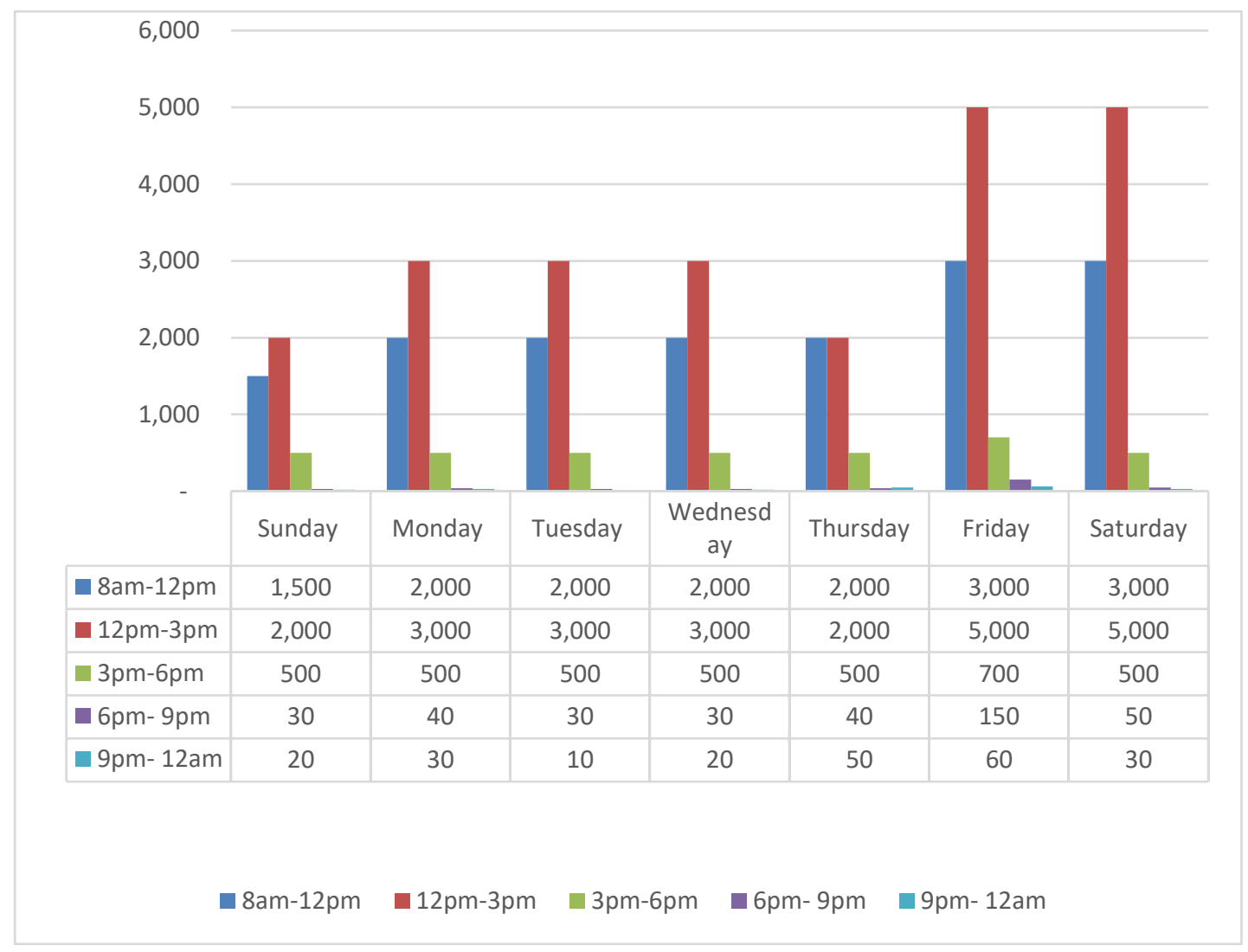

Fig .9 Appropriation Frequencies during protesters day 


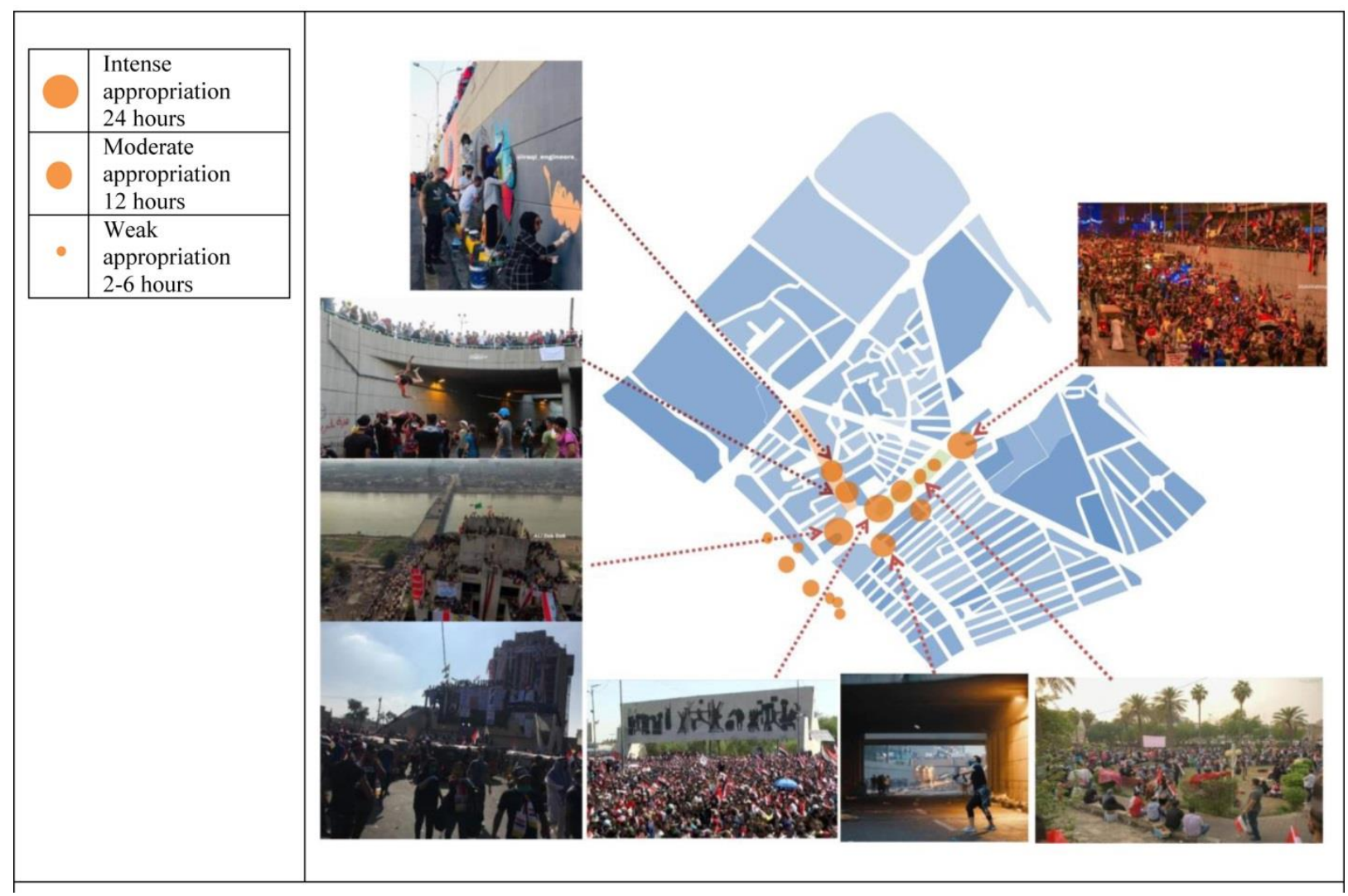

Fig .10. Time duration of appropriation in protester day . Researcher

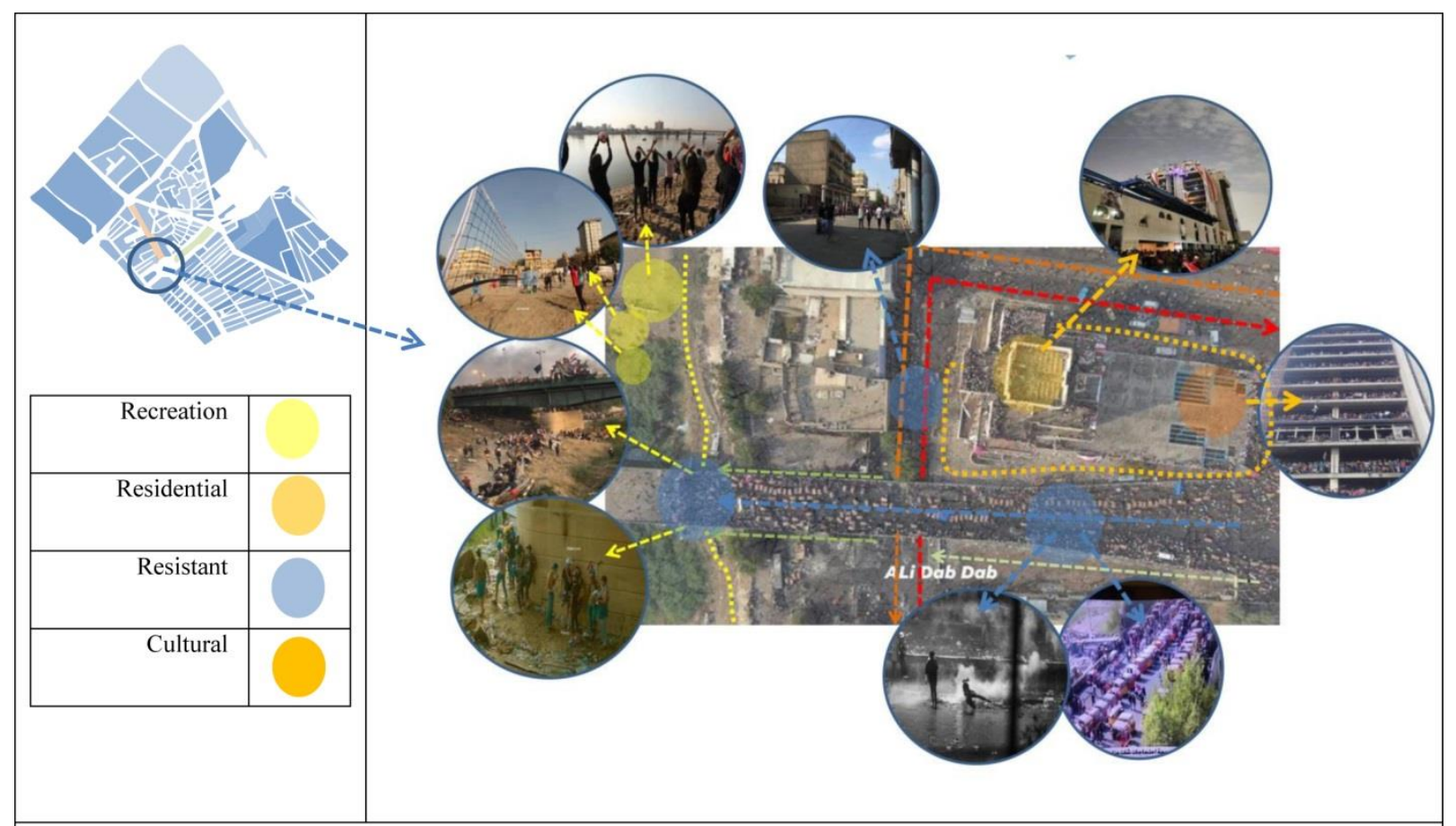

Fig. 11. types of democratic appropriations / Altahrair - protest against laws 

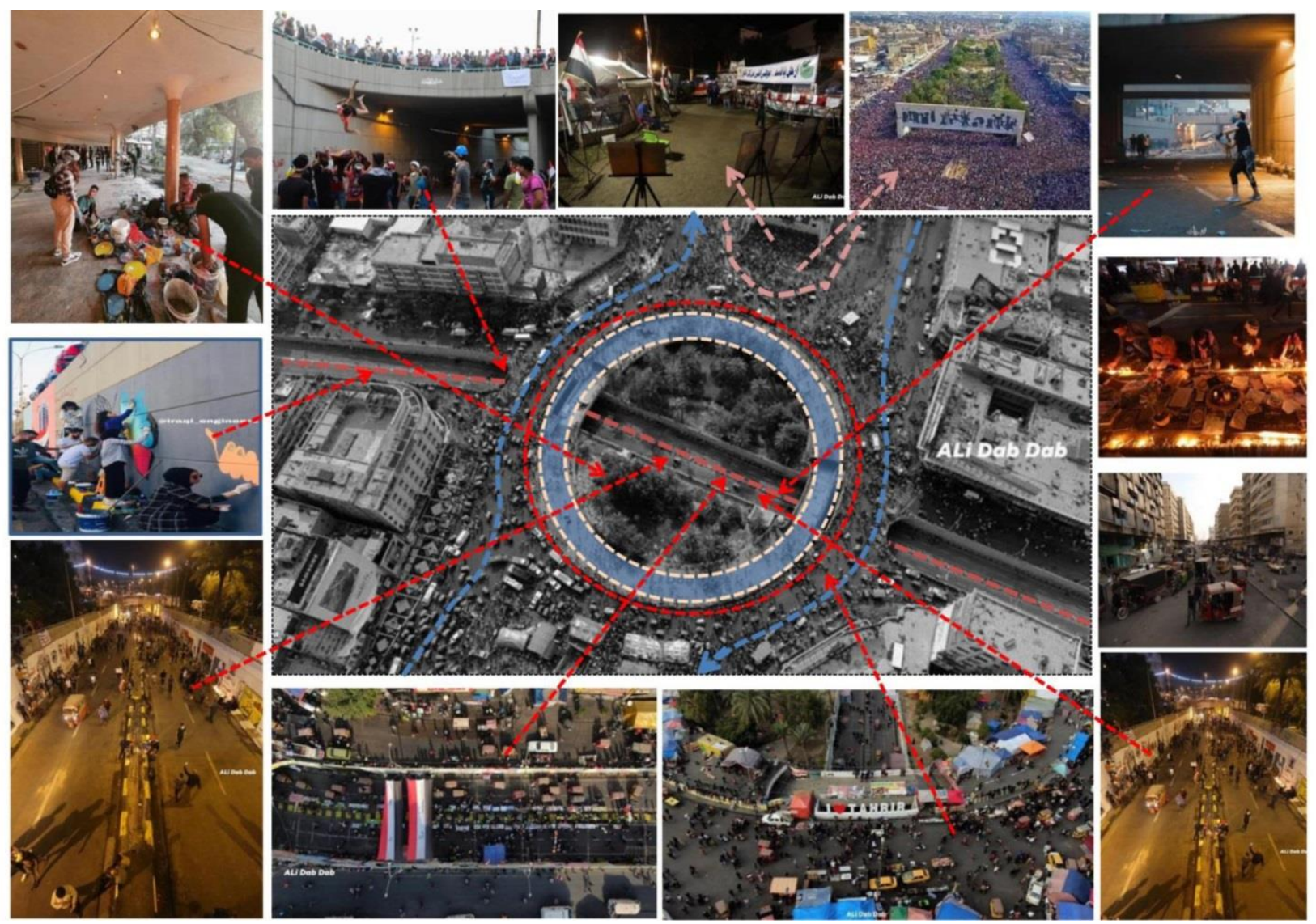

Fig .12. types of protester Appropriations transfers rigid daily spaces into loose spaces / Altahrair -

\section{5- Conclusion and future recommendation:}

- Appropriation in loose spaces is temporal and transformative, it changes according to the urban situation and events took places in urban environment.

- Appropriation affected by social and political events, stimulate users s creativity in using spaces in different way to satisfy their needs.

- Appropriation satisfies people's right in the city, making full use of neglected and abounded spaces transforming it to positive spaces in the city.

- Types of appropriation differs during the day, week, month and can show different types some of them negatives others are positive.

- Time duration of appropriations differs according to its type, place and people's acceptability and needs for it, it can last for minutes or transform to permanent places. Its end determined by local authorities.

- Some types of appropriation transforms daily life spaces into new interactive social space while others can be found in parallel with fixed and intentional use of space.

- Appropriation design spaces from down to top, represents people needs and desires in these spaces, authorities and decision makers should take these appropriations in consider when redeveloping the area.

- $\quad$ Appropriation can give clones for how to develop neglected spaces, and make full use of its potentials in organizing the city

Acknowledgments .Nada has contributed this article as part of PHD dissertation project "hidden rhythm in loose spaces ". We hope this contribution finds your goals . 


\section{References}

[1]Ameel.L , Tani.S.: Parkour: creating loose spaces?. DOI: 10.1111/ j.1468-0467.2012.00393.x ( 2012).

[2] Antonio.J, Hernandez.L, Melis.A, Lehmann.S.: Using the street in Mexico City Centre. Vol. 3 n. 3. P5 . The Journal of Public Space . (2019).

[3] Bishop.P.: Bridge . Reaktion Books Ltd . p. 36. (2008) .

[4] Carmona.M, ,Heath.T, Oc.T . Tiesdell.S : Public Places - Urban Spaces.The Dimensions of Urban Design . Architectural Press. An imprint of Elsevier.p.208(2003).

[5] Crawford.M.: The World In a Shopping Mall . in Sorkin (ed.) Variations on a Theme Park, New York : Hill and Wang . 1999

[6] Erdi-lelandais .G.: Understanding the City: Henri Lefebvre and Urban Studies. Cambridge Scholars .p. (2014).

[7] Frank.A. Paxon.L.: Transformong Public Space into Sites of Mourning and Free Expresssion in: Frank.A,Stevens.Q(ed) Loose Space : Possibility and diversity in Urban Life . Routledge. USA.p.132 (2007).

[8] Frank.A,Stevens.Q(ed) Loose Space : Possibility and diversity in Urban Life . Routledge.USA . p.13 (2007).

[9] Gehl .J.: Life Between Buildings using public space, Island Press, Washington, London.p.19 (2011)

[10] Gelfand.M, L. Raver.J, Nishii.L [et al]. DOI: 10.1126/science.1197754. p.1100-1102 (2011).

[11] Jacobs.j.: The Death and Life Of Great American Cities ,New Work, Vintage.p.25. (1961)

[12] Jimenez.B.: Urban Appropriation and Loose Spaces in the, Guadalajara Cityscape,in Loose space. Routledge.USA .p.96(2007) .

[13] Lefevre.H . the production of space . Wiley-Blackwell. 1992, p.12

[14] merriam-webster definition of loose space in since $1828 \mathrm{https} / / / \mathrm{www} . \mathrm{merriam}-\mathrm{webster} . \mathrm{com} /$ dictionary/loose

[15] Nielsen.T.: the return of the expressive : superfluous landscape. DOI: 10.1177/1206331202005001006 .p.21.( 2002)

[16] Oswalt, P., Overmeyer, K. and Misselwitz. Urban Catalyst: The Power of Temporary Use, DOM publisher Berlin/ Germany. P. 52. (2013).

[17] Purcell, M.: "Excavating Lefebvre: the Right to the City and its Urban Politics of the Inhabitant." GeoJournal, 58(2-3): 99-108 .p.( 2002).

[18] Rivlin, L.G.: Found spaces: Freedom of choice in public life. In Franck, K.A., Stevens, Q. (Eds.). Loose Space: Diversity and Possibility in Urban Life. New York: Routledge. P. 39 (2006) .

[19] Shaw.p Hudson.J. The Qualities of Informal Space: (Re)appropriation within the informal, interstitial spaces of the city.aper presented at $1^{\text {st }}$ conference Occupation: Negotiations with Constructed Space . University of Brighton . ID:132. 2nd to 4th July (2009).

[20] Stevens.Q,Franck.K.: Memorials as Spaces of Engagement: Design, Use and Meaning, , Routledge, New York. P.228. .(2016)

[21] Tani.S.: Loosening/tightening spaces in the geographies of hanging out, Social \& Cultural Geography, Vol. 16, No. 2, (Online) Journal homepage : http://dx.doi.org/10.1080/14649365.2014.952324 . p. (2014) Tani.S, 2015, P128

[22 ] Vocabulary Dictionary meaning of looseness in https://www.vocabulary.com/dictionary/looseness 